\section{Ileal obstruction after duodenal metallic stent placement}
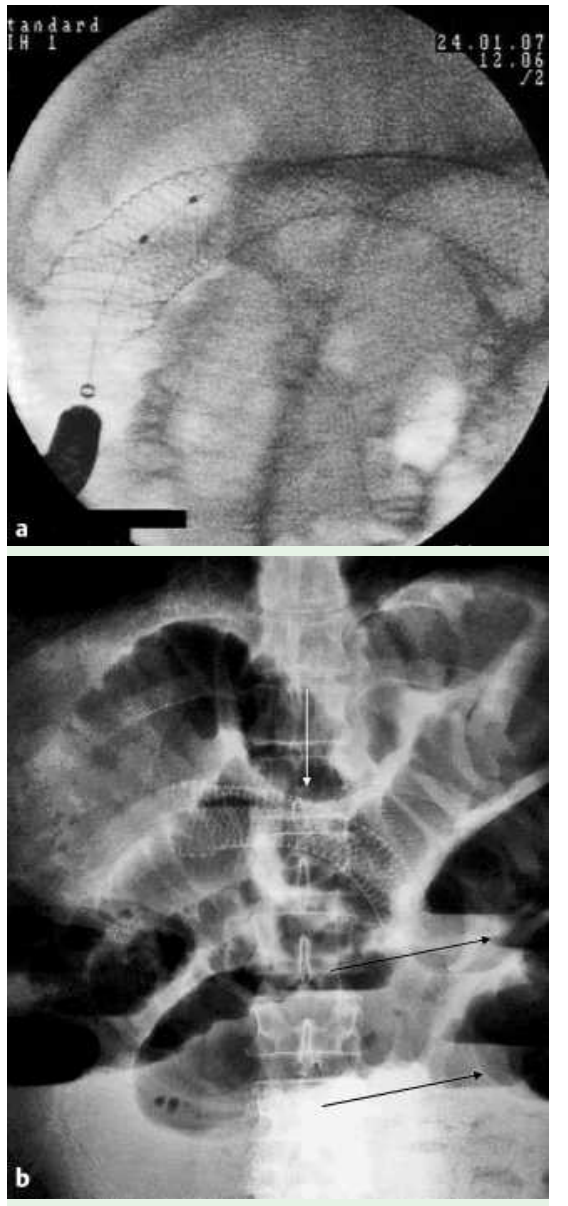

Fig. 1 a View after placement of the duodenal self-expandable metallic stent. $\mathbf{b}$ Upright abdominal radiography. Note the gas/fluid levels (black arrows) 7 days after the stent (white arrow) placement.

A 45-year-old man was admitted to our department, with the symptoms of gastric outlet obstruction. A gastric adenocancer metastatic to the liver had been diagnosed at an another institute 10 days previously. Endoscopy revealed pyloric obstruction due to advanced carcinoma of the gastric antrum. Abdominal computed tomography showed the gastric malignancy and liver metastases, and no lesions of the small or large bowel. An uncovered, $20 \mathrm{~mm} \times 12 \mathrm{~cm}$, self-expandable metallic stent (Ultraflex; Boston Scientific, Ireland) was deployed without any complication ( $\bullet$ Fig. 1 a). The patient began to feed orally the next day, and we re-
Fig. 2 a lleal segment with metastatic tumor infiltration (arrow). b Laparotomy led to a palliative side-to-side ileo-ileal anastomosis.

ferred him to the medical oncology department for evaluation for chemotherapy.

The patient was readmitted with abdominal pain and constipation 7 days after the stent placement. The abdomen was distended with generalized rebound tenderness. Endoscopy excluded stent migration, and upright abdominal radiography revealed gas/fluid levels ( $\bullet$ Fig. $\mathbf{1}$ b). At laparotomy, although ascites was absent, he was found to have a tumoral infiltration compressing the ileum ( $\bullet$ Fig. 2 a). A palliative side-to-side ileo-ileal anastomosis was performed ( $\bullet$ Fig. $\mathbf{2}$ b). Histopathological examination of the biopsy specimen taken from the ileal lesion revealed adenocarcinoma. The patient is still alive 45 days after the palliative operation for intestinal obstruction.

Distal gastrointestinal tract obstruction may be concealed in gastric cancer patients with gastric outlet obstruction as these patients cannot feed orally. This case demonstrates the importance of wide investigation for possible tumoral obstruction of the small or large bowel before a duodenal stent is placed for palliation.

Endoscopy_UCTN_Code_CPL_1AH_2AD

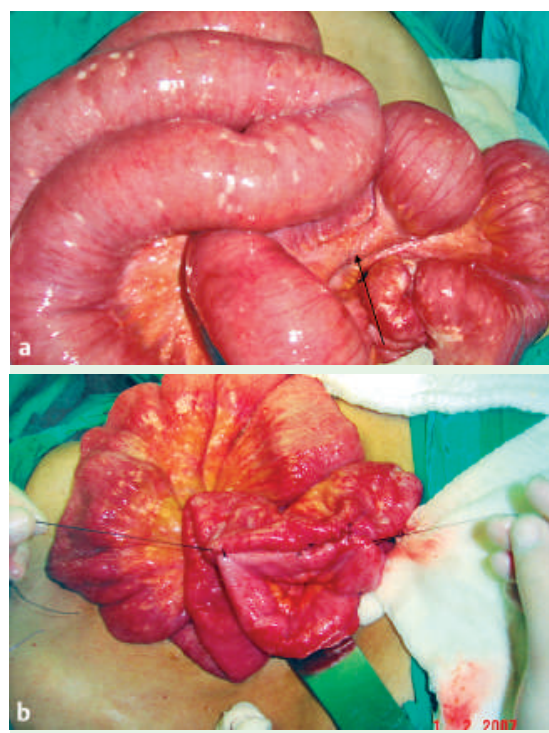

Bibliography

DOI $10.1055 / \mathrm{s}-2007-966726$

Endoscopy 2007; 39: E288

(c) Georg Thieme Verlag KG Stuttgart · New York · ISSN 0013-726X

\section{Corresponding author}

\section{F. Tekin, MD}

Ege Universitesi Tip Fakultesi

Gastroenteroloji Bilim Dali

Bornova 35100

Izmir

Turkey

Fax: +90-232-3427764

drtekinfatih@yahoo.com 